1

PUBLISHED VERSION: Lowery, C.M. and Fraass, A.J. (2019). Morphospace expansion paces taxonomic diversification after end Cretaceous mass extinction. Nature Ecology and Evolution v. 3, 900-904.

https://doi.org/10.1038/s41559-019-0835-0

*NEWS AND VIEWS:* Weil, A. and Kirchner, J.W. "Diversity on the rebound." https://doi.org/10.1038/s41559$\underline{019-0883-5}$

\title{
Morphospace expansion paces taxonomic diversification after end Cretaceous mass extinction
}

\author{
Christopher M. Lowery ${ }^{1}$ and Andrew J. Fraass ${ }^{2,3}$
}

${ }^{1}$ University of Texas Institute for Geophysics

${ }^{2}$ Sam Houston State University

${ }^{3}$ Current Affiliation: University of Bristol, School of Earth Sciences

\section{Abstract}

Highly resolved paleontological records can address a key question about our current climate crisis: How long until the biosphere rebounds from our actions? There are many ways to conceptualize the recovery of the biosphere; here we focus on the global recovery of species diversity. Mass extinction may be expected to be followed by rapid speciation, but the fossil record contains many instances where speciation is delayed, a phenomenon for which we have a poor understanding. A likely explanation for this delay is that extinctions eliminate morphospace as they curtail diversity, and the delay in diversification is a result of the time needed for new innovations to rebuild morphospace which can then be filled out by new species. Here, we test this Morphospace Reconstruction Hypothesis using the morphological complexity of planktic foraminifer tests after the Cretaceous-Paleogene mass extinction. We show that increases in complexity precede changes in diversity, indicating that plankton are colonizing new morphospace and then slowly filling it in. Preliminary diversification is associated with a rapid increase in the 
complexity of groups refilling relict Cretaceous ecospace. Subsequent jumps in complexity are driven by evolutionary innovations (development of spines and photosymbionts) which opened new niche space. The recovery of diversity was paced by the construction of new morphospace, implying a fundamental speed limit on diversification after an extinction event.

\section{2}

\section{Introduction}

Although present rates of extinction do not $\left(\mathrm{yet}^{1}\right)$ rival the Big Five mass extinctions, humanity is undeniably causing elevated rates of biodiversity loss through climate change, habitat destruction, invasive species introduction, etc. ${ }^{1}$ As we seek to mitigate this loss, we must also learn how long it will take for biodiversity and ecosystem functionality to recover after negative anthropogenic effects subside. The Cretaceous-Paleogene (K-Pg) mass extinction, caused by the impact of an asteroid on the Yucatán Platform in the southern Gulf of Mexico $^{2}$, is the most recent and most rapid of the five major mass extinctions and is perhaps the only major event in Earth history which happened faster than modern climate change. Thus, it provides a unique analog for future recovery from rapid extinction.

Following the geologically-instantaneous disappearance of a huge portion of the biosphere, it may be presumed that survivors would rapidly diversify to fill empty ecospace. The global recovery of planktic foraminiferal diversity following the K-Pg mass extinction is a classic example of such explosive adaptive radiation ${ }^{3-7}$. Survivor species, adapted for shallow water and marginal marine environments, gave rise to dozens of new taxa which recolonized the open marine ecospace vacated by the extinction event ${ }^{4,5,8-12}$. This explosive radiation occurred in several pulses, the latter of which were delayed for millions of years ${ }^{3,13-14}$. The initial early Danian burst in diversity only added about twenty species, less than a quarter of pre-extinction diversity ${ }^{11}$. Global richness increased unsteadily throughout the Paleocene, and did not begin to approach even mid- 
51 Cretaceous levels until the Paleocene-Eocene boundary, 10 myr later (Fig. 1A). The full recovery

52 of species- or genus-diversity took more than $20 \mathrm{myr}$, into the middle Eocene ${ }^{18}$, at which point it

53 nearly matched the soaring heights of the Late Cretaceous.

Genus-level macrofaunal diversity data shows that a 10-myr delay in elevated rates of

55 origination is a feature of all mass extinctions, including the $\mathrm{K}-\mathrm{Pg}^{15-17}$. This delay has also been

56 identified in marine plankton after the K-Pg (Fig. 1A) ${ }^{18-20}$, although its cause remains unknown.

57 Explanations have tended toward external environmental controls like the delayed recovery of

58 marine export production ${ }^{4}$, or the persistence of toxic metals or other lingering stressors affecting

59 conditions in the upper water column well after the extinction ${ }^{21}$ possibly driven by Deccan

60 Volcanism ${ }^{22-25}$. Productivity, however, was highly variable in the early Paleocene, with some

61 localities showing a geologically-immediate increase after the extinction ${ }^{26}$. Even considering the

62 longest possible delay in the recovery of global export productivity and the recolonization of

63 deeper habitats ${ }^{13-14}$, about 4 myr, this still does not provide a satisfying explanation for why

64 diversity might remain low for so much longer, up to 20 myr. No evidence of toxic metal

65 enrichments has been found in early Paleocene sediments, and recent work within the Chicxulub

66 Crater, where impact-driven environmental contamination would be worst, documented a rapid

67 recovery there ${ }^{12}$. The lack of a discernable environmental driver has led many authors to propose

68 that ecology, rather than environment, controls diversification after a mass extinction ${ }^{12,26-27}$.

An important ecological control on diversification could be the time needed to reconstruct

70 morphospace within ecosystems ${ }^{16}$, which we term the Morphospace Reconstruction Hypothesis.

71 We often conceive of post-extinction radiations refilling empty niche space, but as Kirchner and

72 Weii ${ }^{16}$ pointed out, the reduction of diversity caused by mass extinctions also destroys niche space

73 (see also Erwin's excellent review ${ }^{28}$ ). Although ecological niches can be conceptualized as slots 
74 in an ecosystem which different organisms can fit into, they are actually created by and are thus

75 inseparable from the organisms which occupy them. In other words, organisms themselves

76 construct the environments they inhabit ${ }^{28}$. This can be more properly conceived of as morphospace

77 (i.e., the range of morphologies occupied by a clade), which represents the range of successful

78 strategies that a clade has made to adapting to its environment and pressure from other organisms ${ }^{28}$.

79 "Ecological niches" are a simplified but handy way of conceptualizing this range of successful 80 adaptations.

Newly colonized morphospace can serve as a jumping-off point for further evolutionary

82 innovation, which in turn opens additional ecospace, and so on, until a clade reaches its limits.

83 Thus, once existing niches are full, additional diversification is dependent on evolutionary

84 innovations to open new niche spaces, a concept borne out by modelling studies ${ }^{19,20}$. The time

85 required to rebuild morphospace is an attractive explanation for the delayed recovery of taxonomic

86 diversity following the K-Pg mass extinction. A large volume of literature has shown that,

87 generally, morphological innovation is expected to lead diversity during radiations, including after

88 mass extinctions ${ }^{28,31-33}$. But these have dealt primarily with higher orders of taxa, had limited

89 temporal resolution, and, to our knowledge, have not explicitly tested the hypothesis that

90 morphospace reconstruction is a limiting factor in diversification. Here, we use a highly resolved

91 (both temporally and taxonomically) fossil dataset, the species-level diversity and morphological

92 complexity of planktic foraminifera after the K-Pg mass extinction, to test the Morphospace

93 Reconstruction Hypothesis.

Complexity (here similar to disparity; see Methods) is calculated from a dataset of ten

95 parameters attempting to capture the large-scale trends in the morphological evolution of the

96 foraminifer test. The simple 'survivor taxa' of the immediate K-Pg recovery had simple 
97 morphologies and broad ecological niches ${ }^{7,9,34}$. Planktic foraminifera may be considered an analog

98 for other zooplankton and larger organisms in the upper ocean which are not as well represented

99 in the fossil record.

If diversification is delayed because of the need for new innovations to open new ecospace,

101 we expect 1) that complexity recovers before diversity, 2) diversification to be associated with

102 large jumps in complexity, suggesting morphospaces are colonized first, and then filled, 3)

103 throwback-type ecospace (i.e., trophic strategies of Cretaceous survivors) to be refilled rapidly

104 after the extinction and then stabilize, and subsequent diversification/increases in complexity to be 105 associated with evolutionary innovations opening new morphospace.

\section{Results/Discussion}

There is a massive drop in mean morphologic complexity at the K-Pg boundary which is 108 evident however complexity is plotted, whether mean or median complexity (Fig 1B), total complexity/diversity (Fig. 1C), or complexity by trophic strategy (Fig. 1D). Unlike diversity (Fig 1A), however, morphologic complexity rebounds more quickly, reaching a plateau near its post-

111 extinction maximum within $\sim 5$ myr. This is roughly coincident with an increase in planktic

112 foraminifer diversity, and is $\sim 1$ myr after the final recovery of surface to deep $\delta^{13} \mathrm{C}$ gradients ${ }^{3}$ and 113 the marine carbon pump ${ }^{35}$. The recovery of morphological complexity indicates that the 114 morphospace occupied by planktic foraminifera has been rebuilt to roughly Cretaceous values. together as mean complexity/diversity (Fig. 1C). If morphospace expands at roughly the same rate 117 as diversity, the mean complexity/diversity timeseries is a flat line; if morphospace is colonized 118 first and then filled out (i.e., new, more complex species colonize a new ecospace, driving increases 
119 in mean complexity) then the mean complexity/diversity timeseries will have a very steep positive

120 slope. This makes mean complexity/diversity the degree of partitioning in the morphospace. The

121 nearly flat line in the Late Cretaceous (Fig. 1C) shows that this interval was characterized by

122 matching increases in complexity and diversity filling out existing morphospace. In the Paleocene,

123 however, morphologic complexity significantly outpaces diversity. We observe three distinct

124 intervals of increased complexity/diversity in the Paleocene (numbered in Fig. 1C), the latter of

125 which are dwarfed by the huge peak in the basal Paleocene. Each of these intervals coincides with

126 an interval of increasing diversity (the climaxes of which are marked with dashed lines on Fig. 1).

127 This is consistent with the observation that morphological complexity tends to increase before

128 taxonomic diversity during radiations ${ }^{31-33}$. Interestingly, the Eocene is associated with roughly flat

129 complexity/diversity, indicating a return to more linear relationship between diversification and 130 morphological change, despite continued diversification.

We can break these trends down further to understand which groups are driving change in

132 each particular interval. Survivors from the Cretaceous were non-spinose and did not have 133 photosymbionts ${ }^{6}$ and were therefore grazers, feeding on phytoplankton and organic detritus; here 134 we call this group of foraminifera "throwback-type" since they represent the most common pre135 extinction lifestyle. The appearance of spines in the basal Paleocene family Globigerinidae allowed 136 these foraminifera and their descendants to adopt a carnivorous lifestyle, feeding on any mobile 137 zooplankton they might snare in their rhizopodal network ${ }^{5}$. The later acquisition of 138 photosymbionts in the mid Paleocene, $\sim 4$ myr after the $\mathrm{K} / \mathrm{Pg}$ extinction, allowed those new genera 139 to supplement their food supply in oligotrophic waters ${ }^{3,13-14}$.

The initial increase in complexity/diversity was driven by both the radiation of throwback141 type forms filling niches similar to those occupied during the Cretaceous and the contemporaneous 
142 radiation of spinose forms colonizing novel ecospace (Fig 1C). Subsequent pulses in 143 complexity/diversity are associated with evolutionary innovations within the new spinose group 144 and the appearance and radiation of symbiont-bearing planktics (Fig 1C).

Overall, our data demonstrate that the generally marginal-marine Cretaceous survivors 146 rapidly reoccupied and diversified within the vacant open-ocean ecospace during the early 147 Paleocene. This interval may be considered the classic "refilling" of vacant niches after an 148 extinction event, but represents more limited morphospace occupation compared to the Late 149 Cretaceous. Because the bulk of morphospace available to planktic foraminifera disappeared along 150 with its inhabitants at the K-Pg boundary, there was a more narrow range of successful life 151 strategies available to planktic foraminifera, and thus diversity at this point is much lower than it 152 was at the end-Cretaceous. Subsequent Paleocene radiations were driven by new evolutionary 153 innovations that opened new morphospace (i.e., pulses in complexity/diversity). This relationship 154 confirms the hypothesis ${ }^{16}$ that the reconstruction of morphospace is a prerequisite for the recovery 155 of diversity after mass extinctions. It also suggests a fundamental speed limit on the rate of 156 diversification.

Throughout their history, the turnover of planktic foraminifera has been driven by both 158 climate $^{36-39}$ and more basic macroevolutionary processes related to biology and ecological 159 interactions between organisms ${ }^{19,40}$. To determine how climate may have affected the trends we 160 observe, we compare our taxonomic and morphometric data with Paleocene-Eocene stable 161 isotopes and key climate events. Following post-K-Pg warming, the Paleocene is characterized by 162 a long, slow cooling and then a slightly faster (and more variable) warming trend leading into the 163 Paleocene Eocene Thermal Maximum (PETM). This is punctuated by a few mild hyperthermal 164 events, including the Dan-C2 event ${ }^{41}$, the Late Danian Event (LDE) ${ }^{42}$, and the Early Late 
165 Paleocene Event $(\mathrm{ELPE})^{43}$. Prior to the obvious turnover at the $\mathrm{PETM}^{18,37}$ there is no clear 166 relationship between either planktic foraminifer diversity or morphologic complexity and any 167 particular climate event or trend. The Dan-C2 hyperthermal occurs after the rapid diversification 168 of the early Paleocene, and that event only lasted $400 \mathrm{kyr}$ and thus doesn't explain the diversity or 169 complexity trends that occur after it. Likewise, our data don't support the hypothesis that Deccan 170 Volcanism impeded the recovery of diversity ${ }^{22-25}$, as the initial diversification in the early Danian 171 occurs well before the end of Deccan volcanism (Figure 2$)^{44}$ during an interval associated with 172 environmental stress at some sites ${ }^{23-25}$. With the LDE we run into the limits of our bin size, as it 173 appears that the evolution of photosymbionts coincides with this event when in reality it preceded 174 it by $\sim 400 \mathrm{kyr}^{45}$ and the radiation of this group occurs after this event ${ }^{46}$. The ELPE occurs during 175 a slight decline in overall diversity, but these trends extend far beyond it. Finally, the PETM clearly 176 exerts an influence on richness at the end of the Paleocene, but this major climatic event is not 177 associated with any changes in morphological complexity, which was already recovered by that 178 point.

This is not to say that climate did not influence the evolution of planktic foraminifera at all 180 through this interval (or the structure of local populations), but that its influence was less important 181 compared to the limit imposed by morphospace occupation. The pulses of evolutionary innovation 182 opening novel morphospace that we describe all occur prior to the obvious turnover at the PETM ${ }^{37}$, 183 and this is also (mostly) the interval of significantly elevated origination rates ${ }^{18}$. However, 184 diversification continues into the Eocene, finally reaching roughly Late Cretaceous values $~ 20$ 185 myr after the extinction ${ }^{18}$. Significant macroevolutionary events throughout the Eocene (and later) 186 are coincident with major climatic events, like the Paleocene-Eocene Thermal Maximum, Eocene 187 Climate Optimum, etc. ${ }^{18}$ This suggests a two-phase period of recovery. In the first phase, the 
Paleocene, diversification was limited by the need to rebuild morphospace, which provided the scaffolding on which to evolve new species. Eventually, morphospace had been expanded to an extent which allowed climate to become the primary driver of diversity. Ezard et al. ${ }^{19}$ showed that a clade's ecology is a key factor in how successful it is in diversifying during different climate states. But after a mass extinction, ecospace must be rebuilt to the point where it can respond to changes in climate. Niche space reconstruction is therefore an essential first step in recovery, and a clear explanation for the observed 10 myr delay in speciation following mass extinction ${ }^{16,17}$.

The generation of novel morphospace after the K-Pg extinction represents stepwise change into a wholly new Cenozoic planktic ecosystem, rather than a return to a mirror-version of the preextinction Cretaceous ecosystem. This should serve as an important reminder ${ }^{16}$ : some ecological niches lost due to anthropogenic climate change will never reappear. While the future biosphere may eventually regain pre-Anthropocene numerical biodiversity levels, it will be significantly different than the biosphere in which we evolved and presently co-exist. This recovery will likely take millions of years.

\section{Figure Captions}

Figure 1. A) Planktic foraminifer diversity from the Late Cretaceous to middle Eocene. Black: throwback-type, Blue: spinose, Green: symbiont-bearing. B) Mean and median test complexity plotted over individual species' complexity values (horizontal lines). C) Mean test complexity divided by diversity. D) Test complexity index by trophic strategy. Grey lines on B and D are individual species. Vertical dashed lines separate the three main peaks in Mean Complexity/Diversity (numbered 1-3 in C). Possible spinose and symbiont species in the 
210 Cretaceous are lumped as "throwback" on the Cretaceous side of this plot because not all

211 Cretaceous planktics have been evaluated for these traits. All survivor species were non-spinose

212 and non-symbiont bearing, and thus these traits had to re-evolve anyway.

214 Figure 2. Comparison of early Paleogene climate events with planktic foraminifer diversity and complexity trends. Oxygen (blue) and carbon (green) isotope curves and key climate events are

216 taken from the Geologic Timescale ${ }^{47}$. Black bar and gray shading show the duration of post K-Pg 217 phase of Deccan volcanism. See Figure 1 for explanation of diversity and complexity plots. Note 218 that apparent mis-ties between boundaries and species ranges are the result the significantly higher 219 resolution of the isotope record compared to our fossil data which is binned at $250 \mathrm{kyr}$.

\section{Methods}

Planktic foraminifer diversity data and species ranges are based on those reported in Fraass

223 et al. ${ }^{18}$, who compiled them from community-based atlas projects ${ }^{48-49}$. Such a global compilation

224 avoids the problems of studying the recovery of diversity/complexity at any particular site, as it

225 avoids the range of possible local effects on species diversity, and allows direct comparison to 226 similar global diversity records ${ }^{15,18,19,29-33,40}$. The species included and their first and last 227 occurrence datums are very similar to other recent efforts (e.g., Aze et al. ${ }^{50}$ ). Morphological 228 complexity was calculated based on the following morphological attributes: circularity of final 229 chamber, apical angle, number of chambers, chamber expansion rate, umbilical view area, the ratio 230 of the final chamber area to the total area, clavateness, keeledness, biconvexity, and lobateness. 231 Detailed explanation of each of these attributes can be found in Kelly et al. ${ }^{37}$. Attributes were 
232 measured primarily from holotypes or images sourced from community-based atlas projects ${ }^{48-49}$.

233 A table showing the interrelationship of the ten morphological attributes is presented in

234 Supplementary Information Table 1. This shows which morphological characters co-vary;

235 although most do not co-vary strongly, some (like the ratio of the final chamber to total test area

236 and expansion rate) do show a linear relationship.

Test complexity was calculated to be a rough estimation of how morphologically complex

each species is, starting with assigning a "simple" morphology. Because describing any

239 morphology as "simple" vs. "complex" is subjective, we define the simplest form as the average

240 of two K-Pg survivor species, Muricohedbergella monmouthensis and M. holmdelensis. We feel

241 these are good avatars of simplicity both because they represent a basic test morphology that was

242 common throughout the Mesozoic and Cenozoic, and because they are the ancestors of many

243 Cenozoic lineages (which become more complex over time ${ }^{49}$ ). The other important K-Pg survivor

244 species, Guembelitria cretacea, is inarguably more complex based on the characteristics laid out

245 in Table S1, and thus was not considered a useful definition of simplicity, although it also gave

246 rise to a number of important and complex Cenozoic taxa ${ }^{49}$. For each attribute the mid-point

247 between monmouthensis and holmdelensis was subtracted, then we took the absolute value of the

248 result. Each attribute was then standardized to a scale of 0-1. Lastly, attributes were added together

249 for each species, providing a score of the difference of each species from our pre-defined 'simple'

250 survivor taxa. This essentially describes the disparity between all other taxa and the average of

251 these two survivors. A principal component analysis, though analytically more complex,

252 demonstrates similar results (see Supplementary Information).

The mean and median complexity of all species within our study interval are reported in

254 Figure 1B. All timeseries were calculated in 250 kyr bins. For mean Test Complexity / Diversity, 
255 mean complexity was calculated as a timeseries, as was diversity, then divided. Code can be found 256 at Github.com/Fraass.

257 Foraminiferal trophic strategies are based on those reported by various authors ${ }^{3,49-50}$ as well 258 as the online database Mikrotax (http://www.mikrotax.org/pforams/ ${ }^{51}$ ). Generally, spinose 259 foraminifera can be identified by careful microstructure examination for the presence of diagnostic 260 spine holes 5 . Symbiont-bearing planktic foraminifera are commonly identified by the stable 261 isotopic signature of their test tend to have tests relatively enriched in ${ }^{13} \mathrm{C}$, caused by the effect of 262 algal photosymbionts on the microhabitat from which the foraminifer precipitates its calcite shell 263 and relatively depleted in ${ }^{18} \mathrm{O}$, indicating a shallow water habitat ${ }^{52}$. Species with neither of these 264 indicators, commonly referred to as microperforate or smooth normal perforate, are observed in 265 the modern ocean to be mainly herbivores, feeding on phytoplankton and detritus ${ }^{5}$.

267 Acknowledgments The authors acknowledge NSF-OCE-1737351 for CML. We are also grateful for the efforts of the scientific drilling community over the last 50 years, collecting the deep sea cores which form the bulk of large datasets like this.

Author Contributions Both authors contributed to data interpretation, figure plotting, and writing and editing the manuscript. AJF wrote the $\mathrm{R}$ Code and performed the morphometric measurements.

Author Information Reprints and permissions information is available at www.nature.com/reprints. The authors declare no competing financial interests. Readers are welcome to comment on the online version of the paper. Correspondence and requests for materials should be addressed to CML (cmlowery@utexas.edu). 
277 Reviewer Information [to come]

278 Competing Interests Statement The authors declare no competing interests.

279 Data Availability Statement All data and code related to this study are available at

280 https://github.com/Fraass.

281 References

282 1. Barnosky, A.D. et al. Has the Earth's sixth mass extinction already arrived? Nature. 471, 51-57

283 (2011).

284 2. Schulte, P. et al. The Chicxulub asteroid impact and mass extinction at the Cretaceous-

285 Paleogene Boundary, Science 327, 1214-1218 (2010).

286 3. Coxall, H. K., D’Hondt, S. \& Zachos, J.C. Pelagic evolution and environmental recovery after 287 the Cretaceous-Paleogene mass extinction, Geology 34, 297-300 (2006).

288 4. Smit, J. Extinction and evolution of planktonic foraminifera after a major impact at the 289 Cretaceous/Tertirary boundary, Geological Society of America Special Paper 190, 329$290 \quad 352(1982)$

291 5. Hemleben, C., Mühlen, D., Olsson, R.K., \& Berggren, W.A., Surface texture and the first 292 occurrence of spines in planktonic foraminifera from the early Tertiary, Geol Jb. 128 117$293146(1991)$.

294 6. Olsson, R.K., Hemleben, C., Berggren, W.A., \& Liu, C. Wall texture classification of planktonic 295 foraminifera genera in the lower Danian. The Journal of Foraminiferal Research 22, 195296 213 (1992). 
7. Arenillas, I., Arz, J., \& Molina, E. A new high-resolution planktic foraminiferal zonation and subzonation for the lower Danian, Lethaia 37, 79-95 (2004).

8. Smit, J., \& Ten Kate, W.G.H.Z. Trace-element patterns at the Cretaceous-Tertiary boundaryconsequences of a large impact, Cretaceous Research 3, 307-332 (1982).

9. D'Hondt, S. \& G. Keller, Some patterns of planktic foraminiferal assemblage turnover at the Cretaceous-Tertiary boundary, Marine Micropaleontology 17, 77-118 (1991).

10. Alegret, L. Arenillas, I. Arz, J.A. \& Molina, E. Foraminiferal event-stratigraphy across the Cretaceous/Paleogene boundary, Neues Jahrbuch für Geologie und Paläontologie Abhandlungen 231, 25-50 (2004).

11. Koutsoukos, E.A.M. Phenotypic plasticity, speciation, and phylogeny in early Danian planktic foraminifera Journal of Foraminiferal Research 44 109-142 (2014).

12. Lowery, C., Bralower, T.J., Owens, J.D., Rodríguez-Tovar, F.J., Jones, H., Whalen, M.T., Claeys, P., Farley, K., Gulick, S.P.S., Morgan, J., \& Exp. 364 Science Party. Rapid Recovery of Life at Ground Zero of the End Cretaceous Mass Extinction, Nature 558 288291 (2018).

13. Birch, H.S., Coxall, H.K., \& Pearson, P.N. Evolutionary ecology of Early Paleocene planktonic foraminifera: size, depth habitat, and symbiosis, Paleobiology 38 374-390 (2012).

14. Birch, H.S., Coxall, H.K., Pearson, P.N., Kroon, D.K., \& Schmidt, D.N. Partial collapse of the marine carbon pump after the Cretaceous-Paleogene boundary, Geology 44 287-290, (2016). 
15. Sepkoski, J.J., Jr. Rates of speciation in the fossil record Phil. Trans. R. Soc. Lond. B $353315-$ 326 (1998).

16. Kirchner, J.W., \& Weil, A. Delayed biological recovery from extinctions throughout the fossil record Nature 404, 177-180 (2000).

17. Alroy, J. Dynamics of origination and extinction in the marine fossil record, PNAS 10511536 11542 (2008).

18. Fraass, A.J., Kelly, D.C., \& Peters, S.E., Macroevolutionary history of the planktic foraminifera Annu. Rev. Earth Planet. Sci. 43, 139-166 (2015)

19. Ezard, T.H.G., Aze, T., Pearson, P.N., \& Purvis, A., Interplay between changing climate and species’ ecology drives macroevolutionary dynamics Science 332, 349-351 (2011).

20. Knoll, A.H.\& Follows, M.J. A bottom-up perspective on ecosystem change in Mesozoic oceans, Proc. R. Soc. B 2832016755 (2016).

21. Jiang, S. Bralower, T. J. Patzkowsky, M. E., Kump, L. R. \& Schueth, J.D. Geographic controls on nannoplankton extinction across the Cretaceous/Paleogene Boundary, Nature Geoscience 2010, 280-285 (2010).

22. Renne, P.R., Sprain, C.J., Richards, M.A., Self, S., Vanderkluysen, L., \& Pande, K. State shift in Deccan volcanism at the Cretaceous-Paleogene boundary, possibly induced by impact, Science 350 76-78 (2015).

23. Gertsch, B., Keller, G., Adatte, T., Garg, R., Prasad, V., Berner, Z., \& Fleitmann, D. Environmental effects of Deccan volcanism across the Cretaceous-Tertiary transition in Meghalaya, India, Earth and Planetary Science Letters 310 272-285 (2011). 
24. Punekar, J., Mateo, P., \& Keller, G. Effects of Deccan volcanism on paleoenvironment and planktic foraminifera: A global survey, Geological Society of America Special Papers $\mathbf{5 0 5}$ 91-116 (2014).

25. Punekar, J., Keller, G., Khozyem, H., Hamming, C., Adatte, T., Tantawy, A.A., \& Spangenberg, J.E. Late Maastrichtian-early Danian high-stress environments and delayed recovery linked to Deccan volcanism, Cretaceous Research 49 63-82 (2014).

26. Hull, P. M. \& Norris, R.D. Diverse patterns of ocean export productivity change across the Cretaceous-Paleogene boundary: New insights from biogenic barium, Paleoceanography 26 PA3205 (2011).

27. Schueth, J. D. Bralower, T. J., Jiang, S. \& Patzkowsky, M. E. The role of regional survivor incumbency in the evolutionary recovery of calcareous nannoplankton from the Cretaceous/Paleogene (K/Pg) mass extinction, Paleobiology 41, 661-679 (2015).

28. Erwin, D.H. Disparity: morphological pattern and developmental context, Paleontology 50, $57-73(2007)$.

29. Solé, R. V. Montoya, J. S. \& Erwin, D. H. Recovery after mass extinction: evolutionary assembly in large-scale biosphere dynamics, Philosophical Transactions of the Royal Society of London 357, 697-707 (2002).

30. Yedid, G., Ofria, C. A. \& Lenski, R. E. Selective press extinctions, but not random pulse extinctions, cause delayed ecological recovery in communities of digital organisms, The American Naturalist 173, E1 (2009). 
31. Foote, M. Morphological disparity in Ordovician-Devonian crinoids and the early saturation of morphological space, Paleobiology 20 320-344.

32. Wagner, P.J. Paleontological perspectives on morphologic evolution, in Evolution since Darwin: the first 150 years (Sunderland, MA, Sinauer) 451-478 (2010).

33. Hughes, M., Gerber, S., \& Wulls, M.A. Clades reach highest morphological disparity early in their evolution, Proc. Natl. Acad. Sci. 110 13875-13879 (2010).

34. Leckie, R.M. Paleoecology of Mid-Cretaceous planktonic foraminifera: A comparison of open ocean and epicontinental assemblages Micropaleontology 33, 164-176 (1987).

35. Henehan, M.J., Hull, P.M., Penman, D.E., Rae, J.W.B., \& Schmidt, D.N. Biogeochemical significance of pelagic ecosystem function: an end-Cretaceous case study Phil. Trans. $R$. Soc. B 371 doi: 10.1098/rstb.2015.0510 (2016).

36. Malmgren, B.A., Berggren, W.A., \& Lohmann, G.P. Species formation through punctuated gradualism in planktonic foraminifera, Science 225 317-319 (1984).

37. Kelly, C.D., Bralower, T.J., and Zachos, J.C. Evolutionary consequences of the latest Paleocene thermal maximum for tropical planktonic foraminifera Palaeogeograhpy, Palaeoclimatology, Palaeoecology 141 139-161 (1998).

38. Leckie, R.M., Bralower, T.J. \& Chasman, R. Oceanic anoxic events and plankton evolution: Biotic response to tectonic forcing in the mid-Cretaceous, Paleoceanography 17 13-1 (2002). 
39. Brombacher, A., Wilson, P.A., Bailey, I., \& Ezard, T.H.G. The breakdown of static and evolutionary allometries during climatic upheaval, The American Naturalist 190 350-362 (2017).

40. Peters, S.E., Kelly, D.C., \& Fraass, A.J. Oceanographic controls on the diversity and extinction of planktonic foraminifera, Nature 493, 398-401 (2013).

41. Quillévéré, F., Norris, R.D., Kroon, D., \& Wilson, P.A. Transient ocean warming and shifts in carbon reservoirs during the early Danian, EPSL 265 600-615 (2008).

42. Bornemann, A., Schulte, P., Sprong, J., Steurbaut, E., Youssef, M., \& Speijer, R.P. Latest Danian carbon isotope anomaly and associated environmental change in the southern Tethys (Nile Basin, Egypt), J. of the Geological Society, London 166 1135-1142 (2009).

43. Petrizzo, M.R. An early late Paleocene event on Shatsky Rise, northwest Pacific Ocean (ODP Leg 198): evidence from planktonic foraminiferal assemblages. In Bralower, T.J., Premoli Silva, I., and Malone, M.J. (Eds.), Proc. ODP, Sci. Results, 198 1-29 (2005).

44. Schoene, B., Samperton, K.M., Eddy, M.P., Keller, G., Adatte, T., Bowring, S.A., Khadri, S.F.R., \& Gertsch, B. U-Pb geochronology of the Deccan Traps and relation to the endCretaceous mass extinction, Science 347, 182-184 (2015).

45. Jehle, S., Bornemann, A., Deprez, A., \& Speijer, R.P. The impact of the latest Danian Event on planktic foraminifera faunas at ODP Site 1210 (Shatsky Rise, Pacific Ocean) PLOS One 10 e0141644 (2015).

46. Quillévéré, F., \& Norris, R.D. Ecological development of acarininids (planktonic foraminifera) and hydrographic evolution of Paleoecene surface waters, in Wing, S.L., Gingerich, P.D., Schmitz, B., and Thomas, E., eds., Causes and Consequences of Globally Warm Climates 
in the Early Paleogene: Boulder, Colorado, Geological Society of America Special Paper $369223-238$ (2003).

47. Vandenberghe, N, Hilgen, F.J., Speijer, F.J., Ogg, J.G., Gradstein, F.M., Hammer, O., Hollis, C.J., \& Hooker, J.J. The Paleogene period. The Geologic Time Scale, El Sevier, Amsterdam 855-921 (2012).

\section{Methods References}

48. Olsson, D. K., Hemleben, C., Berggren, W. A. \& Huber, B. T. Atlas of Paleocene Planktonic Foraminifera, Smithsonian Contributions to Paleobiology 85, (1999).

49. Mesozoic Planktonic Foraminifera Working Group (Huber, B.T., Coordinator), 2006, Mesozoic Planktonic Foraminiferal Taxonomic Dictionary, www.chronos.org.

50. Aze, T., Ezard, T.H., Purvis, A., Coxall, H.K., Stewart, D.R., Wade, B.S., \& Pearson, P.N. A phylogeny of Cenozoic macroperforate planktonic foraminifera from fossil data Biological Reviews 86, 900-927 (2011).

51. Huber, B.T., Petrizzo, M.R., Young, J.R., Falzoni, F., Gilardoni, S.E., Bown, P.R., \& Wade, B.S. Pforams@microtax: A new online taxonomic database for planktonic foraminifera Micropaleontology, 62 429-438 (2017).

52. Spero, H. Life History and stable isotope geochemistry of planktonic foraminifera The Paleontological Society Papers 4, 7-36 (1998). 